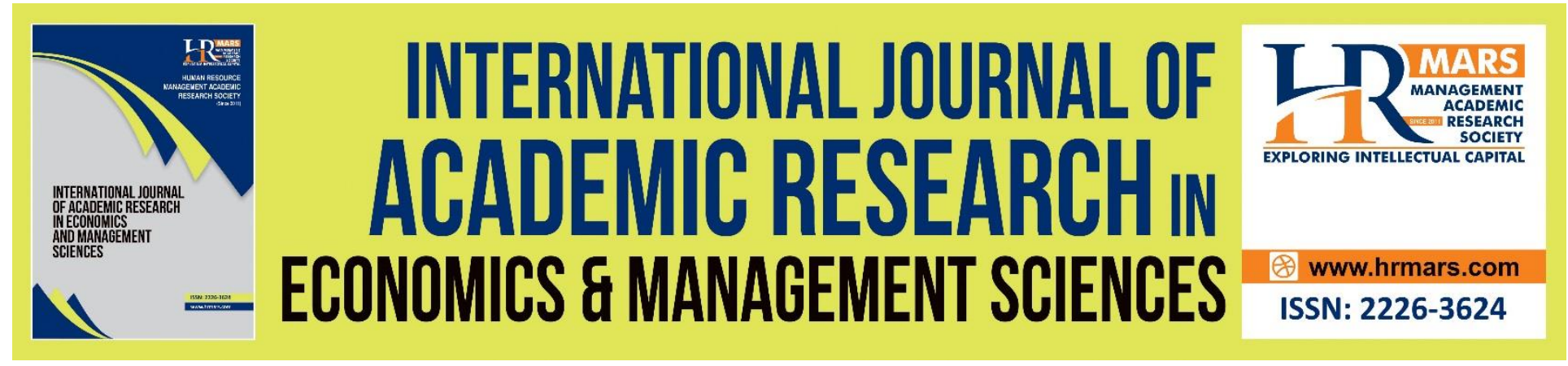

\title{
Micro-business Continuity and Resilience Strategies for COVID-19 Crisis: Entrepreneurs' Insight from Bangladesh
}

Aliya Yesmin, Shiam Rana Aope, Anisur R. Faroque, Urooj Zulfiqar, Alam Md Moshiul, Fariha Anjum Hira

To Link this Article: http://dx.doi.org/10.6007/IJAREMS/v10-i2/9929

DOI:10.6007/IJAREMS/v10-i2/9929

Received: 18 March 2021, Revised: 20 April 2021, Accepted: 10 May 2021

Published Online: 28 May 2021

In-Text Citation: (Yesmin et al., 2021)

To Cite this Article: Yesmin, A., Aope, S. R., Faroque, A. R., Zulfiqar, U., Moshiul, A. M., \& Hira, F. A. (2021). Microbusiness Continuity and Resilience Strategies for COVID-19 Crisis: Entrepreneurs' Insight from Bangladesh. International Journal of Academic Research in Accounting Finance and Management Sciences, 10(2), 33-48.

Copyright: (C) 2021 The Author(s)

Published by Human Resource Management Academic Research Society (www.hrmars.com)

This article is published under the Creative Commons Attribution (CC BY 4.0) license. Anyone may reproduce, distribute, translate and create derivative works of this article (for both commercial and non-commercial purposes), subject to full attribution to the original publication and authors. The full terms of this license may be seen

at: http://creativecommons.org/licences/by/4.0/legalcode

Vol. 10, No. 2, 2021, Pg. 33 - 48

http://hrmars.com/index.php/pages/detail/IJAREMS

JOURNAL HOMEPAGE

Full Terms \& Conditions of access and use can be found at http://hrmars.com/index.php/pages/detail/publication-ethics 


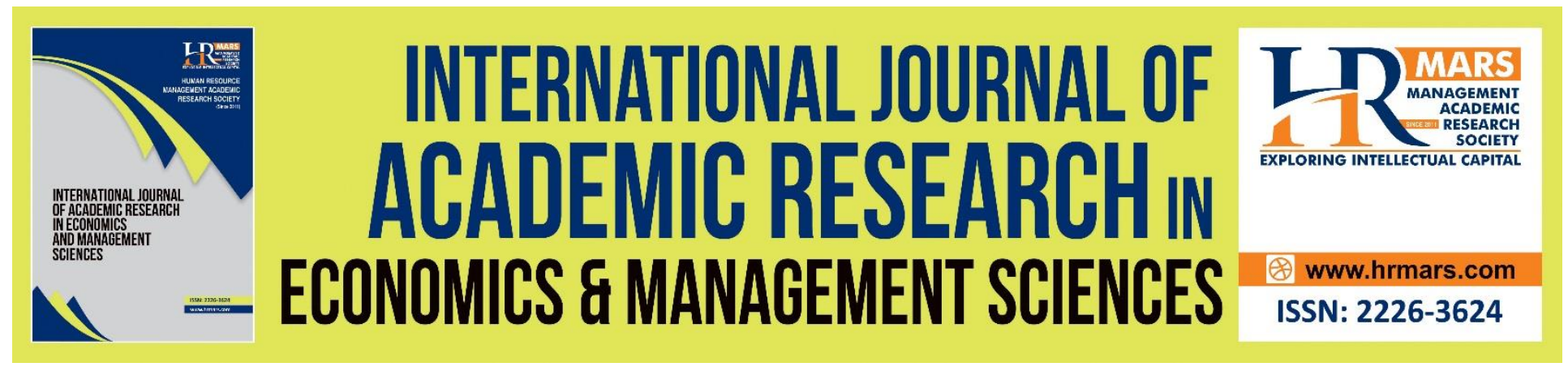

\title{
Micro-business Continuity and Resilience Strategies for COVID-19 Crisis: Entrepreneurs' Insight from Bangladesh
}

\author{
Aliya Yesmin ${ }^{1}$, Shiam Rana Aope ${ }^{2}$, Anisur R. Faroque ${ }^{3}$, Urooj \\ Zulfiqar $^{4}$, Alam Md Moshiul ${ }^{5}$, Fariha Anjum Hira ${ }^{6}$ \\ ${ }^{1,4}$ Department of Business Administration, Azman Hashim International Business School,
} Universiti Teknologi Malaysia (UTM), Johor, Malaysia, ${ }^{2}$ Faculty of Business Studies, University of

Dhaka, Bangladesh, ${ }^{3}$ School of Business and Management, LUT University, Lappeenranta, Finland, ${ }^{5}$ Razak Faculty of Technology and Informatics, Universiti Teknologi Malaysia, Kuala Lumpur, Malaysia, ${ }^{6}$ Azman Hashim International Business School, University Teknologi Malaysia, Kuala Lumpur, Malaysia Email: yaliya@graduate.utm.my

\begin{abstract}
The contribution of micro-businesses is essential towards economic development in Bangladesh. Micro-enterprises provide income and employment opportunities to the people, especially those with low incomes, and offered more affordable goods and services to the public. The recent outbreak of Covid-19 has severely affected the global and Bangladeshi economy. Primary victims of the Covid-19 outbreak are micro-enterprises compared to large enterprises, as they typically do not have enough financial and managerial resources to cope with a disruption that might carry on for an extended period of time. Additionally, these firms are highly dependent on their routine business transactions and a small number of customers. This article aims to assess the impact of the Covid-19 outbreak on these businesses and provide policy recommendations to reduce business losses and survive through the crisis. Covid-19 pandemics have necessitated several travel bans and restrictive measures. In Bangladesh, the country's resistance movement has the strongest impact on the small business sector. In this manner, many entrepreneurs have to suffer business loss, and reduced income as some supporting sectors such as retail and transportation cease to exist. Therefore, there remains little understanding of a global pandemic's implications on micro-entrepreneurs for business continuity and return-planning efforts. Business Continuity Plan tells the organizations how to act during disasters such as coronavirus disease-2019 (COVID19) which organizations usually underestimate can land them in serious troubles. This study represents micro-entrepreneurs views from Narayanganj, Dhaka, in Bangladesh, about the risks and benefits of mobility as a business continuity strategy. The results of unstructured phone interviews provide insights on the business survival approach and recovery plan of micro-
\end{abstract}


enterprises during and after a crisis. Based on the results of the research, different recovery policy recommendations were proposed to ease the adverse effects of the outbreak on microentrepreneurs. The results of this study will hopefully create effective support mechanisms for microentrepreneurs to manage and prosper during and after the crisis. Although our suggested policy recommendations may not be sufficient to help micro-entrepreneurs go through the ongoing crisis, these measures will help them weather the storm.

Keywords: Covid-19 Pandemic, Micro-Enterprise, Business Continuity Strategy, Business Recovery Plan, Bangladesh

\section{Introduction}

Since December 2019, there has been a Novel Coronavirus (Covid-19) respiratory crisis that has extended to more than 200 countries globally, and it reached Asia, Europe, and Australia. This outbreak has been classified as a worldwide epidemic by the WHO (WHO, 2019). An unprecedented increase in human-to-to-human infection (Qiu, Rutherford, \& Mao, 2017) resulted in over 2,000,000 deaths within three months of the outbreak beginning (WHO, 2020). It was still unknown in December of 2019 when severe pneumonia broke out in China. The current outbreak has garnered the attention of the international health community. At the beginning of the year 2020, it is believed to be the center of the disease outbreak; a seafood market in Wuhan has been closed when a new coronavirus was discovered in 2019; it was initially classified as a novel coronavirus, 2019-nCoV, or COVID-19.

Unlike other viruses with high infection and fatalities, a family of coronaviruses, as MERS-CoV and SARS-CoV, appears to have had the highest mortality and case fatality rates (Liu, Ying, et al., 2020). Disclosure of previous research findings contended that frequent movement is the best way to control coronaviruses (Smith \& Freedman, 2020; Sohrabi et al., 2020). Most people affected by coronavirus get affected psychologically and financially during emergency and critical health care ordinances like mandatory closures of stores and interruptions to delivery chains (Karabag, 2020). Southeast Asian countries, including Bangladesh (Bhuiyan et al., 2020), have taken measures like banning their people from leaving, discouraging their people from traveling, and having lost several days due to the Covid-19 outbreak. Initial effort: In the first case, it was detected on March 8, 2020, in Bangladesh. In Bangladesh government initiated a country-wide curfew for one week to neutralise the danger posed by these protests. It also limited the work and consumption times for educational institutions, factories, malls, and shopping malls to start only on the 24th of March 2020 and everything else in the economy. Bangladesh is detecting the exposed population experiencing geometric expansion. According to Banik, Rajon et al. (2020), and Bhuiyan, Israfil, et al.(2020), an epidemiological case is an instance that has been officially confirmed. Confirmed case number: 159,700 and fatalities are 1,997 ( $4^{\text {th }}$ of July 2020, IEDCRInstitute of Epidemiology, Disease Control and Research).

Before making decisions regarding how to reduce or avoid the crisis, it is important to comprehend the definition of crisis. According to Booth (1993), a crisis is something that they are unable to face using ordinary measures. One crisis can occur only gradually; others may be periodic or spontaneous. The Covid-19 can be considered a "crisis", as the whole entity and a part of the economy fell under threat (Booth, 1993); Covid-19 pandemic on the global economy 
can be significant and rapid. Recovery is necessary to continue to thrive in this new and harsh era to survive in a new usual way of living.

However, according to Qamruzzaman (2020), relatively little is known about the troubleshooting and recovery issues confronting small businesses after a crisis. These findings show that a focus on micro-enterprises is most relevant for solving Bangladesh's situation, as these organisations are particularly crucial to the social sector and small and medium-sized enterprises (SMEs). From the government's and key players, it is clear that small business, especially employment generation, is seen as crucial for overall economic development in Bangladesh. Social enterprises and SMEs' contribution to economic growth also extends beyond their contribution to the economy's total GDP. Through social business and SMEs, the Bangladeshi economy experienced significant contributions of $25 \%$ of the GDP; an additional $15 \%$ increase in GDP, an additional $7.8 \%$ in job creation, and $31 \%$ in growth in export advancement with an annual sales turnover of less than 25 lakh BDT, but they employ less than five people (Khan \& Newaz, 2020). Additionally, the number of 649 million ready-to-wear garments manufactured from 738 factories up to $24^{\text {th }}$ March, 2021 amounts to $\$ 2.4$ billion in gross canceled orders recorded (Bangladesh Garment Manufacturers and Exporters Association- BGMEA).

In addition, due to the current quarantine, enterprises not related to emergency food and medicine are suffering immensely. Non-related services or products such as handicrafts, nontradable goods, and goods of all kinds have felt the impact because they have had to cease their production and routine operations. According to the survey in Figure 1 shows, $68 \%$ of the small businesses said that if the lockdown continues for four months or more, they will have to cease operations permanently.

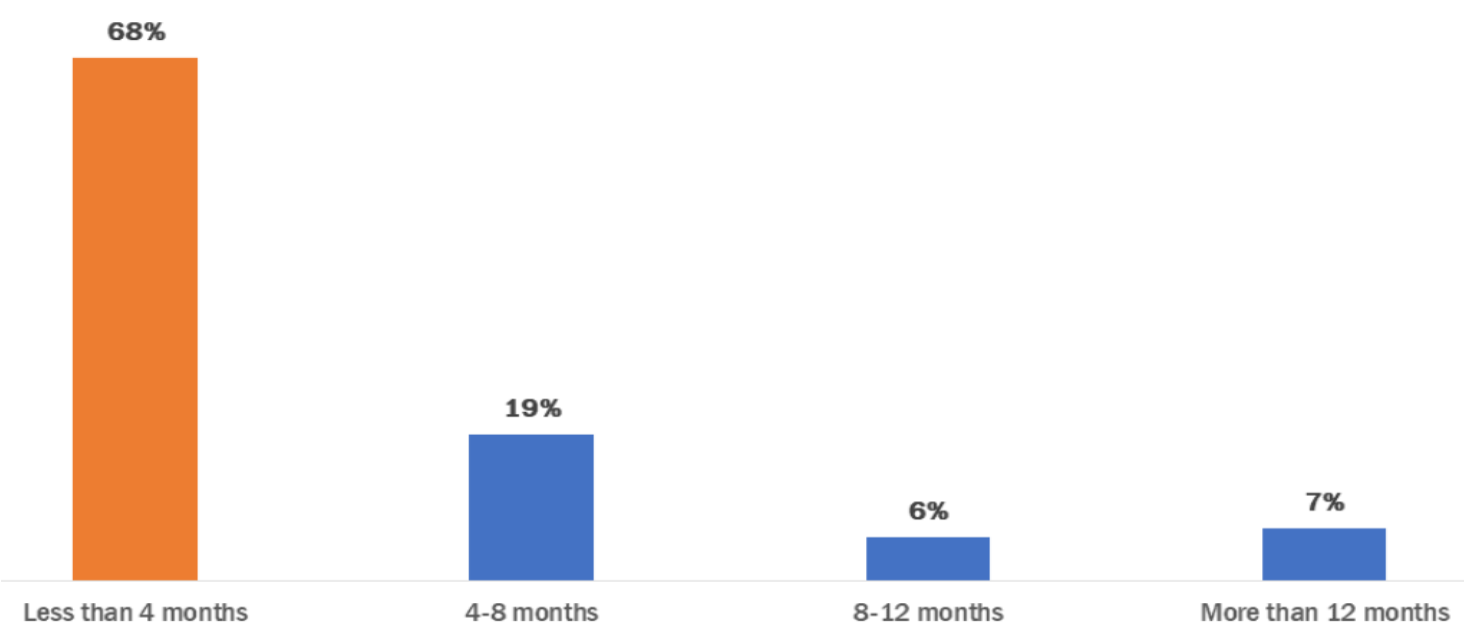

Figure1. $68 \%$ of the small businesses will not survive lockdown more than four months Source: LightCastle Partners and Sheba. A primary survey conducted on April 6-8, 2020 ( $n=230)$

It is reported in numerous studies to be an issue for micro-entrepreneurs to operate in more rural or suburban regions, in contrast to those in urban and developed areas because of the scarcity of workers and limited capital resources (Siemens, 2012; North \& Smallbone, 2007). To 
get a more in-depth understanding of two microentrepreneurs from the Narayanganj city, Dhaka, Bangladesh, this research uses mostly phone interviews to gain insights into how a microenterprise in Bangladesh can respond to control and continuity issues order disruptions in the part of a Covid-19 crisis.

\section{Business Continuity and Resilience Strategy}

In terms of large-company business continuity strategy, several analyses have been performed on businesses that are dependent on manufacturing (Kepnes, 2007) in the developed region (Herbane, 2013). Micro-enterprise studies, however, are relatively few in underdeveloped countries. Most studies on crisis management are focused on epidemic disease outbreaks (Ritchie, 2003), natural disasters (Flynn, 2007; Fabeil et al., 2019), economic and financial crisis (Devece, Ortiz \& Armengot, 2016), and inadvertent disaster and terrorisms (Cook, 2015). While the threat of new and emerging crises like a Covid-19 pandemic has been well-covered, there is still a shortage of literature on its direct impact on micro-enterprises. It is claimed that smaller businesses in non-developed areas are more affected by a crisis than those in urban environments, especially ones of reduced opportunities.

In a crisis or disaster, a business should care about both short-term and long-term profitability. The research study published earlier this year indicated that almost three-quarters of those companies that do not prepare for disaster would fail within three years (Cook, 2015). During crises and disasters, Quarantelli and Lagadi (2007) recommend managing and planning processes. Contingency management means utilising strategies to deal with a crisis, whereas planning anticipates its occurrence. The authors focus on business continuity as an ongoing strategy for entrepreneurs and the design of their strategies as the solution to crises in their plans. Usually, business continuity planning incorporates mitigation and restoration of operations (Cook, 2015). Figure 2 Shows the business continuity process.

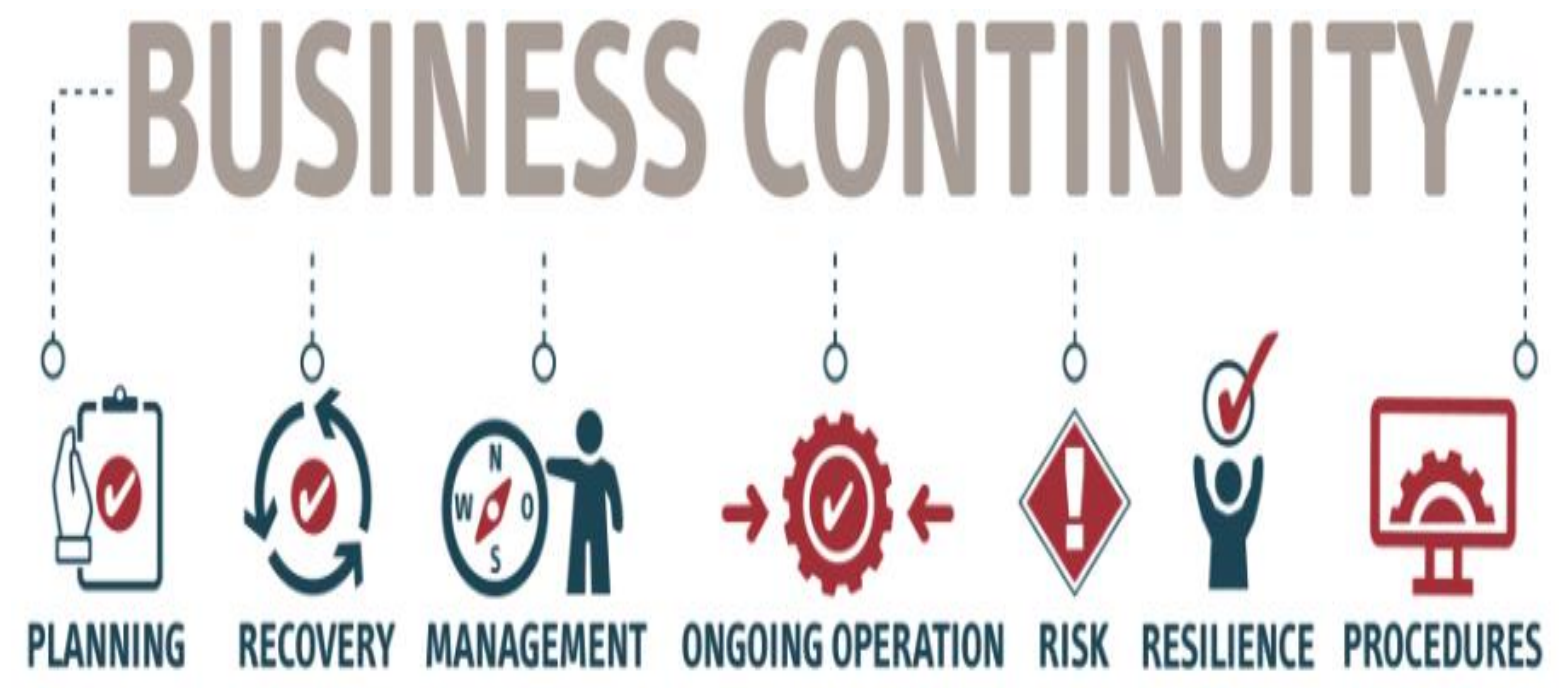

Figure 2: Business continuity process 
Crises bring out the most rational and logical elements in an entrepreneur's thought process, according to McCarthy (2003). Survival mechanisms for handling crises include using alternative channels for marketing, such as doing product reengineering, or of the web (such as the use of low-cost or effective campaigns) in the face of economic competition (Bourletidis \& Triantafyllopoulos, 2014).

In addition, when there is extreme environmental uncertainty, like the current epidemic, small businesses will often fold if they are not able to quickly and deftly change. According to Obschonka et al. (2016), research into Coal Seam Gas (CSG) indicated that local firms were facing economic uncertainty. Some of these businesses experienced growth but struggled because of economic climate change initiatives in their town. Though smaller in scope than the previous recession, researchers discovered the behaviour changes needed during recovery and decline periods. Proactive and relationship with knowledgeable companies could position their offerings at good times like the rise of new technologies and uncertainty in the past. Proactivity and flexibility were important going forward, but financial and human resources were also required to address changing market conditions. Generally speaking, firms will be able to change products and services if the economy gets better. It will be critical for their success to support this by establishing and supporting network relationships and increasing their cooperation. Willingness to change is vital in times of financial transition. The businesses that can respond be open to change and respond well to changes that will prosper. Resilient responses may be researched to understand better how entrepreneurs and their contexts behave, their business models, and how they help shape and/restore socio-economic communities

Bangladesh is likely to see a severe impact on the economy from the Covid-19 pandemic that the Asian Development Bank predicts. Another problem is that the country will lose 3 billion in GDP, roughly $1.1 \%$ of its total. In addition, the country will face a job loss for nine million people (Banna et al., 2020). Another way, the problem is getting worse each day. For instance, currently, 78,000 clothing workers are on strike due to not having received their wages. The country also loses money on textile and leather export and investments from foreign partners like China (people (Banna et al., 2020). As a result, it is evident that Bangladesh will face great economic repercussions if the lockdown continues for an extended period of time. Therefore, the government's support for entrepreneurs to deal with crises should not be considered sufficient in the long term. According to Innovation Design and Entrepreneurship Academy (IDEA, 2020), entrepreneurs should be prepared to follow a new or creative approach during the crisis cycle and use a different method each time, namely, respond, resume, and restore (Cook, 2015).

Furthermore, several studies have looked at managing a crisis; among them are three phases: pre-crisis, crisis, and post-crisis (Fabeil et al., 2019). safety, risk assessment, standard prevention, standard defense, standard response, industrywide risk assessment, and standard learning (Pursiainen, 2018). Based on this current study, researchers have concluded that crisis has a different effect on each stage of a company's movement control phases in Bangladesh. 


\section{Problem Statement}

The first Covid-19 confirmed case was in Bangladesh on March 8, 2020 (WHO, 2020a). The government announced a total country-wide ban on movement for three years to stem the spread of the virus in March of 2020 (Kamruzzaman \& Sakib, 2020). These include those government and private establishments with a specific requirement for health and safety, including telecommunications and transportation (National Committee on Security Affairs (NCSA, 2020). Operating hours for most services sectors are generally are restricted to 810 hours during MCO. In Bangladesh, grocery, convenience stores, restaurants, petrol stations, general stores, and factories cannot operate after 7 pm (WHO, 2020b). Although there was a gradual increase in the second month (World Health Organization, WHO, 2020), many shopping malls started to open for selling events a week before the Eid festival, only two months before the official date of its beginning (Mamun, 2020). Regardless, on or despite that, businesses are still allowed to open for the national pandemic holiday on the designated dates (Shawon, 2020). In underlines, Bangladesh has steadily seen an increase in the prevalence of CO19 cases (WHO, 2020c). The scenario of Bangladesh demonstrates that, when the businesses were allowed to resume, there was still a severe health concern regarding the Covid-19 pandemic (Jaim, 2021).

The media reports show how small businesses have been greatly affected by the lockdown decertification. Microenterprises may experience a loss of daily income because of supply chain disruptions as well as cash available workforces and dipping reserves. Prior research (Khan and Newaz, 2020) on small businesses found that their liquidity issues and operational activities were linked. If the shutdown does not end soon, it reveals that over half of the respondents will have to halt their operations (Khan \& Newaz, 2020). Women business owners in this highly patriarchal country may have more unique problems for their mobility. As many businesspeople moved to alternative practises to continue their operations, the startup continued to find itself in new markets. Other small business owners may pursue several alternative recovery strategies during the startup phase, including selling and promoting their products through social media platforms like Facebook and WhatsApp (Qamruzzaman, 2020). Some of them also chose to hire a part-time shipper to deliver to retail and accepted cash on delivery (COD) as their payment method. However, small businesses in rural areas cannot follow this alternative strategy due to infrastructure limitations.

In addition, The Ministry of Agriculture and the Ministry of Food and Disaster Management (MoFDM) has provided appropriate support and assistance to small enterprise business owners, the agricultural and maritime food industry, including producers and service providers (Sunny et al.2021). The Secretary of the Ministry of Agriculture sent guidelines for his field officers stating that they must "stay in workstations and execute the government order. Stay with the farmers, stay beside the farmers" (Nuhara, 2020). The ministry's recommendation is to enable the farmers' market to function, coordinated by the Department of Agriculture and preserve the perishable products in the supply chain - with a coordinator, which both of which would help end-users get their goods faster from the end of production to consumption (Nuhara, 2020). Agricultural production, food production, and demand have been severely decreased. They can not work their land because they are being prevented from lacking necessary inputs. There is a severe labor shortage, resulting in supply and demand now meeting. Frustration occurs on all 
levels of the supply chain" (Alam et al., 2020). According to Shammi et al. (2020), the government should take proper strategies to protect the agricultural farmers and their crops amidst the pandemic to strengthen the country's food security and maintain the supply chain to consumers.

There is no documented method of implementing a micro-enterprise strategy for business continuity; many industries are only looking at SARS and Ebola previously. However, the study concentrates on large-and rapidly developing ones in developed areas only (Cole \& Watkins, 2015). After studying the effect of the crisis on entrepreneurial firms, Bartz and Winkler (2016) found that small firms have slower growth, indicating their softness compared to large ones. However, in terms of business crises, they are less prone to growth than the larger firms. Some claim that crises are damaging to micro-enterprises; thus, businesses should design and practise plans for dealing with these issues in advance to forestall them.

\section{Research Objectives}

The authors have attempted to examine the crisis management strategy from a microentrepreneur's perspective during an aftermath crisis. This study involves phone interviews with six micro-entrepreneurs during the second phase in Bangladesh. The focus of the interview is to understand their business continuity and recovery strategy during the crisis. This study has significant findings for programs concerned with the small business sector, especially in a rural setting, dealing with promoting financial planning during crisis times.

\section{Research Approach}

The aforementioned investigation examined open-ended interviews in Bangladesh, which took place in the second phase of movement control in April 2021. It was an unstructured interview as it gave the opportunity to record the thoughts and ideas of the entrepreneur without interference from academia or social pressure (Marshall \& Rossman, 2006). Six microentrepreneurs (individuals who are micro-entrepreneurs and founded their businesses with annual sales of less than 25 Lakhs) were chosen for the study. The project's purposive sample of participants was determined, based on their experience, to be ideal candidates to give relevant information to the research objectives. By using purposeful sampling, the parsimonious principle is supported. It also allows for simplicity over complexity and the necessity for finding the simplest possible way to describe the given phenomenon (Allen, 2017).

There is evidence that the data has finally reached the level of "saturation" after six (6) interviews. There are no firm guidelines for the minimum sample size in qualitative research; however, there is evidence that Morse (2000) recommends that 30-50 interviews be used for qualitative studies, Creswell (1998) indicates 15 interviews for qualitative studies and Guest, and Johnson (2006) recommends 15 interviews to adhere to these guidelines strictly. Additional information and detail are reached, and when information saturation is met, replication has occurred, and additional coding becomes infeasible (Guest \& Johnson, 2006); hence, this study has met the requirement for data saturation. Interviews were conducted in a 25-30 minute free, fluid manner in nature. Questions were reduced to satisfy participant fatigue while fulfilling the research goal. Interview memos were kept track of the major points from the meeting. Interviews are best utilised when searching for issues a company faces concerning their continuity and 
recovery strategies when a crisis hits. While understanding business continuity and crisis management, the researcher took small business as important because it aids in developing a better understanding of business recovery strategy during a Covid-19 crisis.

\section{Results and Discussion \\ Business Continuity Strategy During Crisis}

There is no doubt that some sort of business continuity plan is essential. The plan becomes a source of reference at the time of a business continuity event or crisis and the blueprint upon which the strategy and tactics of dealing with the event/crisis are designed. In particular, it can provide essential guidance on damage limitation in those short windows of opportunity, often occurring at the beginning of a crisis (Smith, 2003). A Covid-19 incident has created "opportunities beyond business continuity" mentioned by Margherita \& Heikkil̈̈ (2021). Pandemics are significant disruptions to the regular service or delivery of goods within a system. Like extreme disruptions in the supply chain and inefficiencies could cause business and survival to be brought to an end. The devastating impacts of manufacturing, services, and retail and commerce on the environment are magnified when international trade is linked or globalised (Papadopoulos, Baltas \& Balta, 2020; Senyo, Liu, \& Effah, 2019).

Interviews show that entrepreneurs, especially Agri- based use several synchronous strategies to ensure the operation of their business, particularly (i) decentralised supply chains for short-chain, (non-justified) shipped goods, (ii) customers are hungry for essential foods and shopping necessities, and (iii) Facebook and WhatsApp are digitalized through mobile applications, which allow for the "collect on delivery" method or "cash on-demand," and (iv)getting paid via bank transfer or "cash on request". While they consider 'centralised wholesale 'frozen food hub' a necessity, the study also suggests that a market of perishable produce (e.g., fish, vegetables, and fruits) be created, selling things which are labeled as 'frozen food hub' and must be maintained constantly frozen in place (i.e., fresh). Multiple study locations were mentioned as being appropriate by respondents, as well as governmental buildings, academic, and primary settings. For 'perishable and agricultural products' (retail) products, 'direct sales location's approach' was suggested by Yu-jian (2008). The method of alternative distribution, which is applied by the majority of startup entrepreneurs, is illustrated in Figure 3. Respondents argued for the utility of this approach during this uncertain time, troubled time, and seeing it as something that could be put in place when conditions were better. 


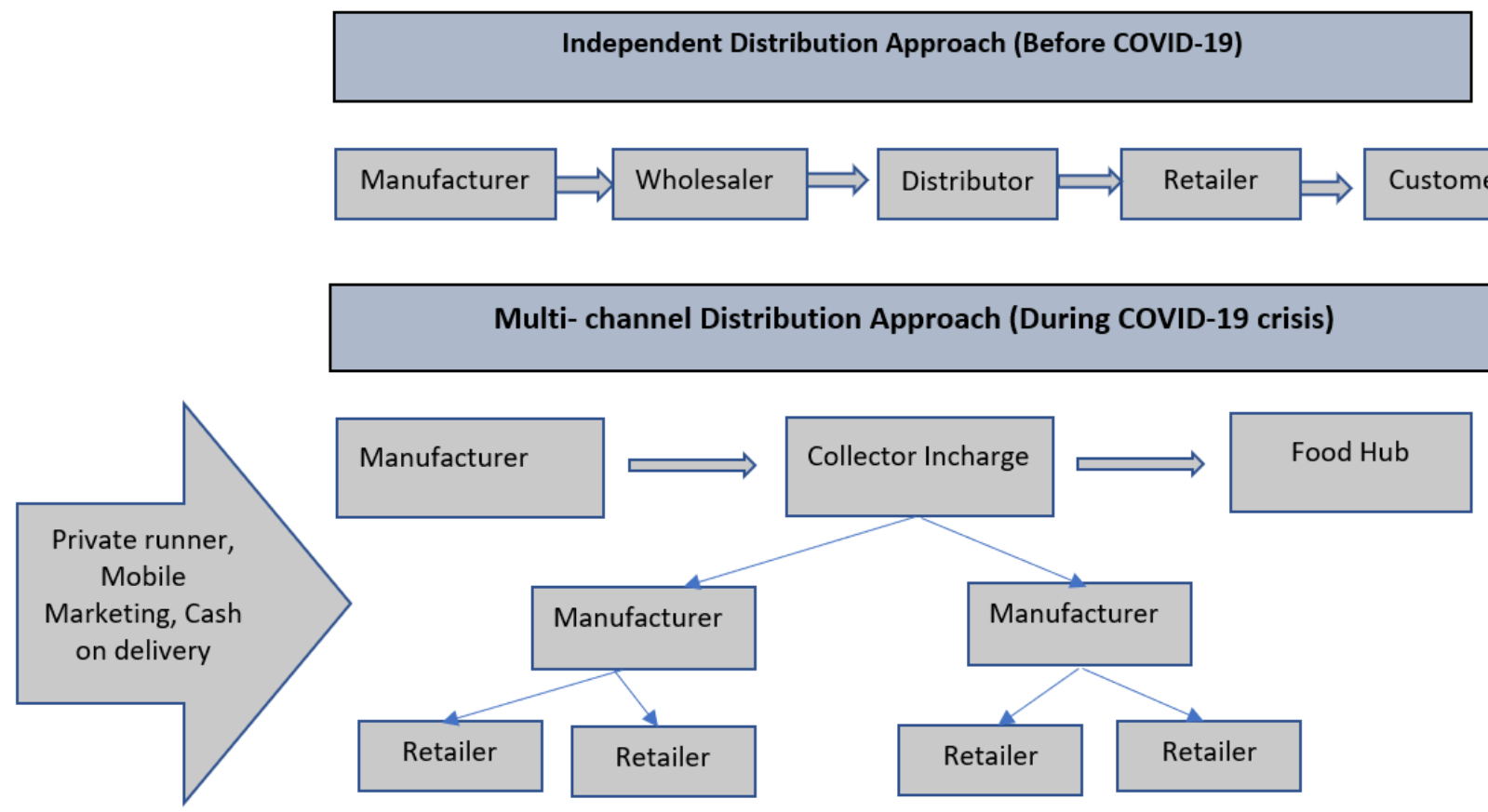

\section{Business Recovery Plan after crisis}

To note, Hamdan, Kassim \& Lai (2021) believe that creative business strategies play a key role in businesses' current and future performance. There is evidence that entrepreneurs behave more logically in the face of a crisis. Several creative strategies are available for businesses during times of crisis, including innovation in marketing (Naidoo, 2010), alternative distribution (Yu-ian, 2008), and cheap and efficient online advertising (Bletis \& Triaf, 2014) and establishing new and varied products and services for the social ecology (Lai, Toh, and Alkhrabsheh, 2020).

Over 12 months have passed since the outbreak of Covid-19 in Bangladesh has gone into a second phase. According to the information, the outbreak of the pandemic has had an impact on microbusinesses in different degrees of disruption. Small businesses started halting activity for a month before the imposition of movement control in Bangladesh. By far, the greatest effect was experienced at the start of the blackout phase, which was later downgraded and reduced over time. A crisis caused the entrepreneur to notice that demand for consumable goods and sanitation supplies has decreased, leading to their assumption that their intent to purchase needs has increased. The more entrepreneurial the business is, the more necessary flexible financial adjustments are to ensure continuous growth.

When a crisis is imminent, there are several approaches to handle business recovery. During an entrepreneurs' business recovery, the strategy consists of responding, resuming, recovering, and restoring (Cook, 2015). This study is detailing the business recovery strategies for micro-business owners in Bangladesh in the second phase of the process of establishing their companies. Table 1 depicts quite a few different business recovery strategies in a time of crisis - before, during, and aftermath. 
INTERNATIONAL JOURNAL OF ACADEMIC RESEARCH ECONOMICS AND MANAGEMENT SCIENCES Vol. 10, No. 2, 2021, E-ISSN: 2226-3624 ㄷ 2021 HRMARS

Table 1. Strategies for Business Recovery in time of Crisis

\begin{tabular}{|c|c|c|c|c|}
\hline $\begin{array}{c}\text { Crisis } \\
\text { Phases }\end{array}$ & Pre- Crisis & \multicolumn{2}{|c|}{ During Crisis } & Post-Crisis \\
\hline Phases & $\begin{array}{l}1 \text { month before } \\
\text { crisis }\end{array}$ & Phase 1 & Phase 2 & $\begin{array}{c}12 \text { months after } \\
\text { crisis }\end{array}$ \\
\hline $\begin{array}{l}\text { Level of } \\
\text { Impact on } \\
\text { income } \\
\text { reduction }\end{array}$ & $80 \%$ & $70 \%$ & $50 \%$ & Less than $5 \%$ \\
\hline $\begin{array}{l}\text { Business } \\
\text { situation }\end{array}$ & $\begin{array}{ll}\text { - } & \text { Full-day } \\
\text { open } \\
\text { - } & \text { business } \\
& \text { as usual }\end{array}$ & $\begin{array}{ll}- & \text { half-day open } \\
- & \text { business from } \\
\text { home }\end{array}$ & 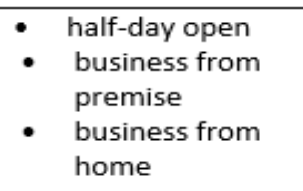 & $\begin{array}{l}\text { Business in the 'new } \\
\text { normal' procedures }\end{array}$ \\
\hline $\begin{array}{l}\text { Impact } \\
\text { reduction } \\
\text { approach }\end{array}$ & None & 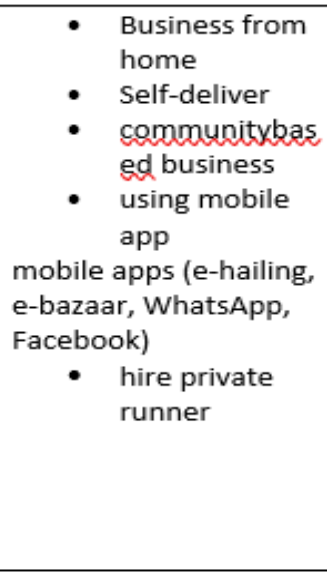 & $\begin{array}{l}\text { Plan for 'new } \\
\text { normal' business:- } \\
\text { - Cash on delivery } \\
\text { - } \quad \text { Private runner } \\
\text { - Communitybase } \\
\text { d channel } \\
\text { - Digital } \\
\text { marketing }\end{array}$ & 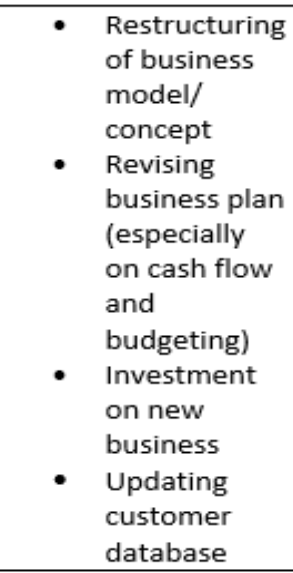 \\
\hline \multirow[t]{2}{*}{$\begin{array}{l}\text { Crisis } \\
\text { phases } \\
\text { (Cook, } \\
2015 \text { ) }\end{array}$} & Warning & \multirow{2}{*}{\multicolumn{2}{|c|}{ Responding, Resuming, Recovering }} & \\
\hline & & & & Restoring \\
\hline
\end{tabular}

Source: The analysis was based on interviews with six microentrepreneurs

There was no stated crisis management or contingency planning of any kind conducted for microentrepreneurs in the interviews. However, various approaches were used to minimize the crisis's effects, including running the business from home, digital marketing, and market penetration of the new segments. According to the research conducted by Cook (2015), responding, resuming, recovering, and regaining are strategies that entrepreneurship takes through time, equal to the various crises. The impact-reduction strategies undertaken by entrepreneurs in this study are parallel with crisis phases, as suggested by Cook (2015), which involve responding, resuming, recovering, and restoring. Some of the interviewed executives said that this could be viewed as the "restoration stage, the twelve-month timeframe between a crisis and when things are once again operating as usual. During this early recovery period, an entrepreneur is likely to have acquired a significant amount of experiences, skills, and resources to be redirected. Such knowledge has formed the fundamental part of the business recovery plan, like implementing an entirely new business model or restructuring the business plan and 
revising the market segments in light of today's circumstances, such as learning to run the business with new normalised procedures.

\section{Conclusion}

Because of the Covid-19 pandemic, there was a partial lockdown, an increase in transmission and the community's burden, and economic decline and disruption; the pandemic had a negative effect on GDP. It has created several problems in the socio-economic and psychological worlds because of deaths and lost jobs. The government should take action to improve risk assessment, communications, and mental health. The study seeks to investigate the Covid-19 pandemic crisis impact on micro-entrepreneurs in Narayanganj city of Bangladesh, which was conducted in April 2021, and understand the impact reduction approach in dealing with the crisis. As the crisis is categorized as a 'sudden threat' micro-entrepreneurs, business challenges can be categorized into two main themes, namely business continuity and recovery strategy. Meanwhile, microentrepreneurs approaches in reducing the effects of the crisis can be viewed as adjusting to the new norms.

The conclusion is that micro-enterprises have no management strategies; nevertheless, their mitigation of a crisis appears more ad hoc. Entrepreneurship seemed to be demonstrated in their company by implementing product delivery and marketing recovery strategies while managing to stay alive in the market. Crises often stimulate entrepreneurs to be more analytical and deliberate, according to this study (McCarthy, 2003). Interestingly, the respondents saw the government's economic stimulus fund as having no influence on the financial crisis. Entrepreneurs seemed to demonstrate their ability to survive in their business by undertaking several business continuity approaches and recovery strategies, especially in terms of product delivery and marketing. This finding is parallel to McCarthy (2003), who suggested that the experience of crisis leads entrepreneurs to act more rationally and engage in planning when making decisions. Interestingly, the respondents viewed the economic stimulus fund provided by the government as a non-paramount remedy to reduce the impact of the crisis. It is harder for microentrepreneurs in less-developed areas to provide support and facilities because of this. Crushnahan's study (2004) examined the impact of environmental stress on rural Indonesian tourism. In order to keep microentrepreneurs (i.e.self-employed entrepreneurs) in business, it is necessary to help them when they are in a crisis, specifically in terms of teaching them how to handle problems. The specialised knowledge like online marketing, product development, pricing strategies, supply procedures, and creating a customer database could be a good starting point for a micro-enterprise crisis management plan. Our suggested policy measures may not be enough to help micro-entrepreneurs survive during the current crisis, but these measures would be very constructive to ease the suffering of these businesses during a difficult time.

Despite the fact, our research provides insightful theoretical and practical implications concerning the impact of Covid-19 on micro-enterprises. Yet, some limitations remain in this research that provides room for further research. This study is limited in that it focuses primarily on results from six respondents only. Regardless, the research which was conducted on the interviews contributed to the existing body of literature that examines how small business firms respond to crisis and business continuity issues. Additional survey research using a wider 
respondents/participants pool is required in future studies to better understand the microenterprise survival mechanism throughout the crisis. Besides creating social and economic consequences, the outbreak of Covid-19 has created new challenges for protecting the health and safety of employees and customers and a new workplace operational culture. Hence, future studies can also consider examining these issues to provide more in-depth knowledge about the consequences of the ongoing pandemic on businesses to understand its survival mechanisms better.

\section{References}

Qiu, W., Rutherford, S., Mao, A., \& Chu, C. (2017). The pandemic and its impacts. Health, culture and society, 9, 1-11.

Cook, J. (2015). A six-stage business continuity and disaster recovery planning cycle. SAM Advanced Management Journal, 80(3), 22-33.

Palmatier, R. W., Sivadas, E., Stern, L. W., \& El-Ansary, A. I. (2020). Marketing Channel Strategy: An Omni-Channel Approach.

WHO. (2020). World Health Organisation (2020). Coronavirus disease (Covid-2019) situation reports. Retrieved from https://www.who.int/emergencies/diseases/novelcoronavirus2019/situation-reports/

Smith, W., \& Freedman, D. O. (2020). Isolation, quarantine, social distancing and community containment: pivotal role for old-style public health measures in the novel coronavirus (2019-nCoV) outbreak, Journal of Travel Medicine, 27 (2).

Sohrabi, C., Alsafi, Z., O'Neill, N., Khan, M., Kerwan, A., Al-Jabir, A., Iosifidis, C., \& Agha, R. (2020). World Health Organization declares global emergency: A review of the 2019 novel coronavirus (COVID-19), International Journal of Surgery, 76, pp. 71-76

Liu, Y., Gayle, A. A., Wilder-Smith, A., \& Rocklöv, J. (2020). The reproductive number of COVID-19 is higher compared to SARS coronavirus. Journal of travel medicine.

Bhuiyan, A. I., Sakib, N., Pakpour, A. H., Griffiths, M. D., \& Mamun, M. A. (2020). COVID-19-related suicides in Bangladesh due to lockdown and economic factors: case study evidence from media reports. International Journal of Mental Health and Addiction, 1-6.

Banik, R., Rahman, M., Sikder, T., \& Gozal, D. (2020). COVID-19 in Bangladesh: Public awareness and insufficient health facility remain key challenges. Public health.

Booth, S. (1993). Crisis management. Competition and change in modern enterprises, TJ Press Ltd, London.

Qamruzzaman, M. (2020). COVID-19 Impact on SMEs in Bangladesh: An Investigation of What They Are Experiencing and How They Are Managing? Available at SSRN 3654126.

Siemens, L. (2012). Challenges, responses and available resources: success in rural small businesses. Journal of Small Business and Entrepreneurship, 23(1), 65-80,

North, D., \& Smallbone, D. (2007). Developing entrepreneurship and enterprise in Europe's peripheral rural areas: Some issues facing policy-makers. Journal of European Planning Studies, 14(1), 41-60

Kepenach, R. J. (2007). Business continuity plan design. Proceeding of the Second International Conference on Internet Monitoring and Protection, 1-5 July 2007, USA. IEEE, http://dx.doi.org/ 10.1109/ICIMP.2007.11 
Herbane, B. (2013). Exploring crisis management in UK small and medium sized enterprises. Journal of Contingencies and Crisis Management, 21(2),82-95.

Ritchie, B. W. (2003). Chaos, crises and disasters: a strategic approach to crisis management in the tourism industry, Tourism Management, 25(6), pp. 669-683.

Flynn, D. T. (2007). The impact of disasters on small business disaster planning: a case study, Disasters, 31(4), 508-515.

Fabeil, N. F., Marzuki, K. M., Razli, I. A., Majid, M. R. A., \& Pawan, M. T. A. (2019). The impact of earthquake on small business performance: evidence from small accommodation services in Ranau, Sabah, International Academic Journal of Business Management, 6(1), 301-313. http://dx.doi.org/ 10.9756/IAJBM/V6I1/1910031

Quarantelli, E. L., Lagadec, P., \& Boin, A. (2007) A Heuristic approach to future disasters and crises: New, old, and in-between types, Handbook of Disaster Research, 16-41.

Turner, B. L., Kasperson, R. E., Matson, P. A., McCarthy, J. J., Corell, R. W., Christensen, L., \& Schiller, A. (2003). A framework for vulnerability analysis in sustainability science. Proceedings of the national academy of sciences, 100(14), 8074-8079.

Bourletidis, K., \& Triantafyllopoulos, Y. (2014). SMEs survival in time of crisis: strategies, tactics and commercial success stories. Procedia-Social and Behavioral Sciences, 148, 639-644.

Obschonka, M., Stuetzer, M., Audretsch, D. B., Rentfrow, P. J., Potter, J., \& Gosling, S. D. (2016). Macropsychological factors predict regional economic resilience during a major economic crisis. Social Psychological and Personality Science, 7(2), 95-104.

Banna, M. H. A., Sayeed, A., Kundu, S., Christopher, E., Hasan, M. T., Begum, M. R., \& Khan, M. S. I. (2020). The impact of the COVID-19 pandemic on the mental health of the adult population in Bangladesh: a nationwide cross-sectional study. International Journal of Environmental Health Research, 1-12.

Alam, M. S., Ali, M. J., Bhuiyan, A. B., Solaiman, M., \& Rahman, M. A. (2020). THE IMPACT OF COVID-19 PANDEMIC ON THE ECONOMIC GROWTH IN BANGLADESH: A CONCEPTUAL REVIEW. American Economic \& Social Review, 6(2), 1-12.

Jaim, J. (2021). Exist or exit? Women business-owners in Bangladesh during COVID-19. Gender, Work \& Organization, 28, 209-226.

Khan, O. F., \& Newaz, A. (2020). COVID-19: Impact on Bangladesh's SME landscape. Retrieved from https://www. lightcastlebd.com/insights/2020/04/25/covid-19-impact-onbangladeshs-sme-landscape

World Health Organization (WHO). (2020a). WHO Bangladesh COVID-19 situation report \# 4. Retrieved from https://www. who.int/docs/defaultsource/searo/bangladesh/covid-19who-bangladesh-situation-reports/who-ban-covid-19-sitrep10.pdf?sfvrsn1/4c0aac0b8_4

World Health Organization (WHO). (2020b). WHO Bangladesh COVID-19 situation report \# 10. Retrieved from https://www. who.int/docs/defaultsource/searo/bangladesh/covid-19who-bangladesh-situation-reports/who-ban-covid-19-sitrep10.pdf?sfvrsn1/4c0aac0b8_4

World Health Organization (WHO). (2020c). WHO Bangladesh COVID-19 situation report \# 14. Retrieved from https://www. who.int/docs/default-source/searo/bangladesh/covid-19who-bangladesh-situation-reports/who-ban-covid-19-sitrep14-

20200601.pdf?sfvrsn $1 \frac{4657 b 0 f 1 b \_4}{}$

Smith, D. (2003). Business continuity and crisis management. Management Quarterly, 44(1), 2733. 
Bodrud-Doza, M., Shammi, M., Bahlman, L., Islam, A. R. M., \& Rahman, M. (2020). Psychosocial and socio-economic crisis in Bangladesh due to COVID-19 pandemic: a perception-based assessment. Frontiers in public health, 8, 341.

Kamruzzaman, M., \& Sakib, S. M. N. (2020). Bangladesh imposes total lockdown over COVID-19. Retrieved from https://www. aa.com.tr/en/asia-pacific/bangladesh-imposes-totallockdown-over-covid-19/1778272

Mamun, S. (2020). Eid amid Covid-19 pandemic: Limited opening of shopping malls on Sunday. Dhaka Tribune. Retrieved from https://www.dhakatribune.com/bangladesh/2020/05/08/eid-in-covid-19-limitedopening-ofshopping-malls-tomorrow

Cole, J., \& Watkins, C. (2015). International employees' concerns during serious disease outbreaks and the potential impact on business continuity: Lessons identified from the 2014-15 West African Ebola outbreak. Journal of business continuity \& emergency planning, 9(2), 149-162.

Bartz, W., \& Winkler, A. (2016). Flexible or fragile? The growth performance of small and young businesses during the global financial crisis-Evidence from Germany. Journal of Business Venturing, 31(2), 196-215.

Allen-Leigh, B., Uribe-Zúñiga, P., León-Maldonado, L., Brown, B. J., Lörincz, A., Salmeron, J., \& Lazcano-Ponce, E. (2017). Barriers to HPV self-sampling and cytology among low-income indigenous women in rural areas of a middle-income setting: a qualitative study. $B M C$ cancer, 17(1), 1-11.

Morse, J. M. (2000). Determining sample size.

Creswell, J. A. (1998). Five qualitative traditions of inquiry. Qualitative inquiry and research design. Choosing among five traditions, 47-72.

Guest, G., Bunce, A., \& Johnson, L. (2006). How many interviews are enough? An experiment with data saturation and variability. Field methods, 18(1), 59-82.

Margherita, A., \& Heikkil̈̈, M. (2021). Business Continuity in the COVID-19 Emergency: A Framework of Actions Undertaken by World-Leading Companies. Business Horizons.

Papadopoulos, T., Baltas, K. N., \& Balta, M. E. (2020). The use of digital technologies by small and medium enterprises during COVID-19: Implications for theory and practice. International Journal of Information Management, 55, 102192.

Senyo, P. K., Liu, K., \& Effah, J. (2019). Digital business ecosystem: Literature review and a framework for future research. International Journal of Information Management, 47, 5264.

Yu-lian, W. (2008). The Optimization Model of Distribution Channels Farm Produce in Heilongjiang Province. Commercial Research, Issue 4.

Hamdan, N. H. B., Kassim, S. B. H., \& Lai, P. C. (2021). THE COVID-19 PANDEMIC CRISIS ON MICROENTREPRENEURS IN MALAYSIA: IMPACT AND MITIGATION APPROACHES. Journal of Global Business and Social Entrepreneurship (GBSE), 7(20).

Naidoo, V. (2010). Firm survival through a crisis: The influence of market orientation, marketing innovation and business strategy. Industrial marketing management, 39(8), 1311-1320.

Lai, P. C., Toh, E. B., \& Alkhrabsheh, A. A. (2020). Empirical Study of Single Platform E-Payment in South East Asia. In Strategies and Tools for Managing Connected Consumers (pp. 252-278). IGI Global. 
INTERNATIONAL JOURNAL OF ACADEMIC RESEARCH ECONOMICS AND MANAGEMENT SCIENCES Vol. 10, No. 2, 2021, E-ISSN: 2226-3624 @ 2021 HRMARS

McCarthy, C. (2003). Learning on the Job: Moving From Faculty to Administration, 2003(123), 3949. 